\title{
Sexual Knowledge, Desires, and Experience of Adolescents and Young Adults With an Autism Spectrum Disorder: An Exploratory Study
}

\author{
Christian C. Joyal ${ }^{1 *}$, Julie Carpentier ${ }^{2}$, Suzie McKinnon ${ }^{3,4}$, Claude L. Normand ${ }^{4,5}$ and \\ Marie-Hélène Poulin ${ }^{4,6}$ \\ ${ }^{1}$ Department of Psychology, Université du Québec à Trois-Rivières, Trois-Rivières, QC, Canada, ${ }^{2}$ Department of \\ Psychoeducation, Université du Québec à Trois-Rivières, Trois-Rivières, QC, Canada, ${ }^{3}$ Integrated University Health and \\ Social Services Centre (IUHSSC) of Saguenay-Lac-Saint-Jean, IUHSSC Bas-Saint-Laurent and IUHSSC Côte-Nord, \\ Saguenay, QC, Canada, ${ }^{4}$ Intellectual Disability and Autism Spectrum Disorder Research Institute, IUHSSC of Mauricie and \\ Centre-du-Québec, Trois-Rivières, QC, Canada, ${ }^{5}$ Department of Psychoeducation and Psychology, Université du Québec en \\ Outaouais, Gatineau, QC, Canada, ${ }^{6}$ Department of Psychoeducation, Université du Québec en Abitibi-Témiscamingue, \\ Rouyn-Noranda, QC, Canada
}

OPEN ACCESS

Edited by:

Jeffrey C. Glennon,

University College Dublin, Ireland

Reviewed by:

Mark Andrew Stokes,

Deakin University, Australia Ashleigh Hillier,

University of Massachusetts Lowell,

United States

*Correspondence:

Christian C. Joyal

christian.joyal@uqtr.ca

Specialty section:

This article was submitted to

Autism,

a section of the journal

Frontiers in Psychiatry

Received: 24 March 2021

Accepted: 03 May 2021

Published: 09 June 2021

Citation:

Joyal CC, Carpentier J, McKinnon S, Normand CL and Poulin M-H (2021)

Sexual Knowledge, Desires, and

Experience of Adolescents and Young Adults With an Autism Spectrum Disorder: An Exploratory Study. Front. Psychiatry 12:685256. doi: 10.3389/fpsyt.2021.685256
Although most persons with an Autism Spectrum Disorder (ASD) wish to have romantic and/or sexual relationships, little is known about self-report sexuality of adolescents/young adults with ASD. In this exploratory study, 172 male and female adolescents/young adults (68 with ASD and 104 without ASD) completed an online version of the Sexual Behavior Scale-Third edition. Although many more similarities than differences were observed between the groups for views and desires about romantic relationships (e.g., wishing to have a girlfriend/boyfriend), fewer participants with ASD (mostly boys) had experience with a variety of sexual/dyadic behaviors, and approximately half of girls with ASD reported negative sexual experiences. Significantly higher rates of participants with ASD felt their knowledge about sexuality was limited and found it difficult to understand sexual education compared with typically developing (TD) participants. Significantly lower rates of participants with ASD reported that they identify to their assigned gender compared with TD participants. Multiple regressions revealed that being older at first diagnosis and possessing better knowledge about sexuality were significant predictors of both positive and negative sexual experience. This study explores strengths and challenges related with the sexual health of adolescents/young adults with ASD and implications for clinical and educational practice are discussed.

Keywords: autism spectrum disorder, sexuality, adolescent, asperger, young adult

\section{INTRODUCTION}

Adults with Autism Spectrum Disorder (ASD) have particular challenges to face in their attempts to be involved in romantic/sexual relationships and they engage, on average, in fewer socio-sexual behaviors than typically developing (TD) individuals (1-3). Personal (e.g., difficulties in social cognition), institutional (e.g., insufficient sexual education), and societal (e.g., ableism, 
assumptions, stigmatization, and exclusion) barriers contribute to limit the sexual knowledge of people with ASD (especially adolescents) and lower their chances to have romantic/sexual relationships (2). This type of data is of utmost importance as it helps developing education or training plans based on specific needs of persons with ASD to initiate and maintain romantic/sexual relationships. However, available studies are mostly limited to adults and information gathered from adolescents/young adults with ASD is warranted.

Adolescence and the transition into adulthood represent a challenging developmental phase involving important bio-psycho-social modifications (including physical, emotional, social, and cognitive transformations) and intense learning/adaptation (4). One major challenge faced by most adolescents, with or without ASD, is the discovery and exploration of personal and interpersonal sexuality (5). Adolescent sexuality is particularly complex because it is a multidimensional process involving areas as diverse as expanding sexual knowledge (about oneself and others), exploring sexual preference, wanting (or not) to develop intimate partnerships, fulfilling (or not) important socio-sexual needs (e.g., being liked and accepted, giving and receiving affection, feeling attractive, sharing feelings) and confirming (or questioning) gender identity and sexual orientation (6). Although transition into adulthood in general and sexuality in particular are challenging for most adolescents, it might be even more so for those with ASD (7).

Contrary to traditional belief [e.g., (8)], the majority of persons with ASD clearly express desire to have romantic/sexual relationships [e.g., $(9)$, see $(1,10)$ for meta-analyses]. However, available studies about sexual health of persons with ASD are typically based on adult participants or indirect reports from parents or counselors of adolescents, often without comparative data. Given the importance of romantic/sexual exploration and sexual health during adolescence in general and the paucity of data obtained directly from young persons with ASD, the main goal of this exploratory study was to directly ask adolescents and emerging adults with ASD about their sexual knowledge, desires, challenges and experience.

\section{Sexual Knowledge, Desires, and Experience of Adolescents/Young Adults With ASD}

In opposition to the classic assumption that they are too naïve and immature to be interested in sexuality [e.g., (11)], a growing number of studies suggest that most adolescents/young adults with ASD (but not all), just like any person their age, have sociosexual interests, including for dyadic relationships and behaviors (12-16). According to their parents, adolescents/young adults with ASD have, on average, less sexual and privacy knowledge, and they engage less in socially appropriate (and more in inappropriate) sexual behaviors than typically developing (TD) adolescents [e.g., $(13,15)]$. These conclusions are uncertain, however, because parents of children with ASD tend to overestimate their own knowledge about their child's sexual life (17). In addition, these parents tend to underestimate the sexual experience and activities of their child (18-20). As stressed by
Dekker et al. (18), underestimation of sexual behaviors by these parents may reflect not only the fact that most of these behaviors are performed privately, but also that parents might assume that sexuality is non-existent or irrelevant for their child with ASD. Therefore, self-report measures are preferable for the study of sexual desires and behaviors of persons with ASD (21), including adolescents/young adults.

Few studies limited to adolescents or younger adults (i.e., 15-25 y.o.) with ASD have used direct assessment (self-report) of their sexual/romantic knowledge, desires and experience (18, $22,23)$. The majority of these participants express interests in sexuality and want to be involved in a romantic relationship. When a comparison group of TD peers is included, more similitudes than differences are found for sexual knowledge and behaviors compared with adolescents/young adults with ASD. As reported below, these studies contain limitations addressed by the present investigation. Dewinter et al. (23) surveyed male adolescents with ( $n=50$ without intellectual deficits, mean age of 16.7 years, $15-18$ y.o.) or without ( $n=90$ matched on age, educational level, and ethnicity) ASD and found very similar rates of sexual experience between the groups. These interesting results, at odds with most hypotheses based on parent and caregiver reports, might reflect reality, being based on selfreports. However, they might also apply only to younger boys. Approximately 2 years later, a subset of the same participants with $\operatorname{ASD}(n=30$, mean age of 18.6 years) had significantly less sexual experience than TD boys in dyadic behaviors [i.e., partnered sexual behaviors, French kissing, and petting; (24)]. Therefore, adolescents with ASD may be just as sexually active, but have less dyadic sexual experience than their peers.

In another comparative study of self-reported (and parent reported) sexuality of adolescents/young adults with $(n=$ 58 , mean age of 16.8 years, $13-21$ y.o.) and without $(n=$ 91, mean age of 16.3 years) ASD, Dekker et al. (18) found, again, no significant differences between the groups for sexual desires and sexual behaviors. However, the Bonferroni approach ( $\alpha$ /number of comparisons) was adopted to correct multiple comparisons in that study, shrinking the level of significance to a very conservative level (0.0008), thus enhancing the risk of committing type-II errors (25). As acknowledged by the authors, "adolescents with ASD have shown approximately one-third of the sexual behaviors and the TD adolescents about half of the sexual behaviors [of the 41 item sexual/intimate subscale]" (p. 1,732 ). Clearly, the two groups seem to differ in that study, which deserves further self-report investigation.

Taken together, these two comparative studies based on selfreports concluded much more similarity than difference between groups for sexual experience $(18,23)$. However, the fact that the mean age of participants was relatively low in both studies (16.3 years for TD participants in each study) might have induced a ceiling effect for sexual experience. The absence of inter-group differences might also reflect the fact that both studies were conducted in the Netherlands where, perhaps, sexual education provided to adolescents with ASD is better than in other countries. Clearly, there is a need to investigate sexual knowledge and experience with older adolescents/young adults with ASD outside the Netherlands. 
A third investigation on sexual health of adolescents with ASD based on self-report was a qualitative study with 27 participants conducted in the U.S.A. (22). Female participants were more likely than males to report no interest in sexuality and to express fear of being taken advantage of. There were only seven girls in that study, however.

Finally, Fernandes et al. (12) and Hartmann et al. (20) compared responses of adolescents/young adults with ASD to those of their parents. Both studies confirmed that most participants report having sexual interest. Fernandes et al. also found a relatively high rate of participant with paraphilic interests (24\%), associated with symptom severity (higher) and intellectual capacity (lower). Hartmann et al. assessed an online survey to 100 young adults (18-30 y.o.) with ASD. They confirmed that the rate of romantic interest was relatively high (73\%) and knowledge about basic sexual education (e.g., knowing about sexual transmitted diseases) and privacy (e.g., aware of social rules about undressing in private) was good. Still, almost half (46\%) of these participants with ASD reported that they never or rarely seek privacy when they masturbate, with approximately a third (36\%) reporting the same for using the toilet. As stressed by the authors, these results suggest the need for better sexual education among adolescents with ASD. In addition, nearly two-thirds of that sample reported at least one item of both the sexual victimization (62\%) and sexual aggression (65\%) scales. However, this study did not compare rates between genders.

Overall, four of these self-report investigations about sexuality of adolescents/young adults with ASD mostly concerned boys $(12,18,22,23)$ and the fifth did not distinguish between genders (20). More data, especially self-reported, concerning sexual knowledge, desires, and experiences of female adolescents/young adults with ASD are needed, along with comparative data from TD adolescents.

\section{ASD and Sexual Victimization}

Individuals with ASD seem to be at higher risk for sexual victimization than individuals without $A S D$, although evidencebased data are still scarce on that matter [see $(26,27)$ for reviews]. In adults with ASD, a handful of studies are available, indicating high prevalence of sexual victimization, ranging between 46 and $78 \%(20,28-32)$. Not all studies included a comparison group, however. On one study, for instance, the proportion of female college students women reporting unwanted sexual contact on campus was in fact lower among those with ASD compared with those without ASD, although rates were alarmingly high in both groups [61.5 and $83.2 \%$, respectively; (28)]. In young adults with ASD (18-30 years), two independent studies reported a lifetime prevalence of $62 \%$ for sexual victimization $(20,31)$. Earlier data indicated that odds ratios for sexual victimization were equally elevated for men and women with ASD (29), although more recent studies suggested that women with ASD are at significantly higher risks than men with ASD (30). Accordingly, parents of adolescent girls with ASD commonly worry about the risks of sexual exploitation because they feel their child is overly trusting of others (33). Homosexuality could further elevate these risks (34), just as it is the case in the general population [e.g., (35)].

Data concerning the sexual victimization of adolescents/young adults with ASD are also scarce. A prospective Swedish investigation reported that at 18 years old girls but not boys with ASD were significantly more likely to have been sexually victimized than minors without ASD (36). In a Canadian study, rates of sexual victimization before adulthood were similar (55.6 vs. $50 \%$, respectively) between persons with and without ASD (32). Still, odds for sexual assault by a peer were 7.3 higher for those with ASD compared with those without ASD (32). In the same study, rates of sexual victimization during adulthood were also similar between the groups ( 46.7 vs. $40.5 \%$, respectively), although persons with ASD were 3 times more likely to be sexually assaulted by an unknown adult or to be the victim of a rape compared with persons without ASD (32). The relatively low sample sizes in that study prevented comparisons between genders, however. Another study reported a rate of $40.1 \%$ for childhood sexual abuse among women with ASD traits, although no comparison group was included (37). Overall, the few existing studies on sexual victimization of persons with ASD suggest that they are at higher risks than the general population. Possible difference between genders for these risks deserves further investigation.

A potentially important factor for sexual victimization of persons with ASD is socio-sexual knowledge. As could be expected, better capacities in the social and communication domains are associated with higher dyadic sexual well-being and higher sexual satisfaction, arousability, and desire in adults with ASD (38). The link between sexual knowledge and sexual wellbeing among persons with ASD is unclear, however. On one hand, Brown-Lavoie et al. (29) reported that sexual knowledge is significantly and inversely associated with sexual victimization. As stressed by the authors, social skills deficits and lack of sexual knowledge may render individuals with ASD more vulnerable to sexual victimization. It is worth noting, however, that the definition of sexual knowledge in that study was limited to physiological and biological information (i.e., related to sexually transmitted infections, contraception, and reproductive health). On the other hand, the results of a meta-analysis (although based on only nine studies) suggested that females with ASD have both better sexual understanding and more negative sexual experiences than males with ASD (10). It remains possible that relatively better socio-sexual knowledge (e.g., understanding that two lovers can kiss and touch each other under certain circumstances) in persons with ASD increases their risks of being sexually victimized. Given that social and communication abilities are higher, on average, in women than in men with ASD [e.g., (39)], these factors might explain in part gender differences found in risks of sexual victimization.

Another possible risk factor for sexual victimization is age at first diagnosis of ASD. Qualitative data suggest that women with ASD who were diagnosed late (i.e., 15 y.o. or older) are at higher odds to be sexually victimized because they are more likely to be in a relationship or to be interested in dyadic sexuality (40). Therefore, gender, sexual knowledge, and age at 
first diagnosis might represent significant factors for risks of sexual victimization in adults with ASD.

\section{ASD and Sexual Education}

Formal and informal sexual education is of utmost importance for the sexual health of any adolescent/young adult, let alone those with ASD (41). Although most programs of sexual education for persons with ASD focus more on biological content (e.g., anatomy, puberty, reproduction) and self-awareness/safety (e.g., boundaries, assertiveness, privacy) than personal sexuality (e.g., sexual orientation, masturbation) and relationships (e.g., dating, emotions, dyadic behaviors), they significantly improve outcomes (42). For different reasons [including prejudice and stigmatization; (43)], individuals with ASD usually receive less sexual guidance, support and education than their TD peers $(1,3,13,16,44)$. Furthermore, when sexual education classes provide specific information about sexuality, students with ASD report that they do not know how to apply it to life situations (44). In addition, persons with ASD learn significantly less about sexuality and romantic functioning from peers and friends (and more from parents) than TD persons, a type of learning more closely related with real life circumstances $(16,29,44,45)$. As a result, sexual knowledge is more limited for persons with ASD, especially during the crucial period of adolescence or the first years of adulthood $(1,18,20)$. Accordingly, all adolescents/young adults with ASD who took part in a recent qualitative study $(n=$ 27) expressed a need to receive more sexual education (22).

\section{ASD and Sexual Diversity}

Sexual orientation (e.g., non-heterosexuality) and sexual identity (non-cisgender) are more varied or less rigid, on average, in persons with ASD compared with TD individuals [see $(26,27)$ for reviews]. Rates of same-sex behaviors, homosexual orientation or non-exclusive sexual interests are consistently higher in adults with ASD compared with the general population (14, 34, 38, 46-55). In adolescents with ASD, results are mixed. Although lower rates of exclusive heterosexuality $(\sim 60 \%)$ are reported by parents or caregivers $(12,14)$, there is no difference with TD peers according to self-reports $(18,23)$. Still, adolescents with ASD seem to be more inclined to same-sex sexual interactions than their TD peers (23). These mixed results might reflect different proportions of girls included across studies as the effect is more pronounced among women than among men with ASD $(46,48,49,51)$. Different levels of functioning might also be associated with different level of sexual orientation fluidity [with lower levels of functioning being associated with higher odds of non-heterosexual orientation; (52)].

Significantly higher rates of opposite gender identification, non-binary gender, and gender dysphoria are also found in persons with ASD compared with TD individuals (48, 56$60)$. Autistic traits are higher in transgender persons (6164 ), and they are associated with gender variance in TD children $(49,50,65)$.

Self-reports of adults with ASD also indicate higher rates of asexuality $(51,66)$ and lower levels of sexual drive (46) or sexual desire (67), on average, compared with the general population. Women with ASD report less sexual interest, on average, than men with ASD (30). It remains to be seen whether similar conclusions apply to adolescents/young adults with ASD. Anecdotal evidence based on chart reviews suggest that a significant minority of adolescents with ASD seem to be asexual (68).

\section{Objectives}

The main goal of this exploratory study was to gain information about sexual knowledge, desires, challenges, and experience of adolescents and emerging adults with ASD. An additional objective of this study was to compare responses of participants with ASD to those of a comparison group, as well as responses from boys vs. girls to document the nature and importance of difference (if any) between these groups. Negative sexual experience were also considered to explore whether adolescents/young adults with ASD are at higher risk to be sexually victimized compared with their peers and, if it is the case, which type of sexual victimization is most likely to occur. Finally, this study aims at assessing the value of selected variables (age, gender, age at first diagnosis of ASD, sexual knowledge, level of socialization outside family, and desire to have sex with others) to predict general sexual experience and sexual victimization of adolescents/young adults with ASD.

These data will allow obtaining a general picture of the sexual health of young persons with ASD. These selfreported data will also help identifying areas of sexual satisfaction and dissatisfaction expressed by young persons with ASD, which should enable refining educational and clinical programs accordingly.

\section{Research Questions}

This exploratory study attempted to answer the following research questions: (1) What are the strengths and need of adolescents/young adults with ASD in regard with their sexuality? (2) What are the differences, if any, between adolescents/young adults with and without ASD in regard with their sexuality? (3) What are the differences, if any, between boy and girls with ASD in regard with their sexuality? (4) Which recommendations can be made for professionals working in clinical or educational setting in regard with these results?

\section{Hypotheses}

Given its exploratory nature, this study was based only on three broad hypotheses: (1) Whereas adolescents/young adults with ASD will show interest and desires to have dyadic romantic/sexual relationships, they will report having less knowledge and less experience with these relationships than TD adolescents/young adults; (2) Significantly more girls with ASD than both boys with ASD and TD girls will report having negative sexual experience; (3) Gender (girls), age (higher), and sexual knowledge (higher) will represent significant predictors of dyadic positive sexual experience among participants with ASD.

\section{MATERIALS AND METHODS}

\section{Participants}

A total of 194 adolescents/young adults began the survey, of which 172 filled all questions included in this study (mean age: $19.2 \pm 2.7$ ): 68 with ASD (41 boys, mean age: $19.4 \pm 2.9$ 
TABLE 1 | Prevalence and inter-group comparisons of adolescents/young adults with $(n=68)$ and without $(n=104)$ a diagnosis of ASD . $^{1}$

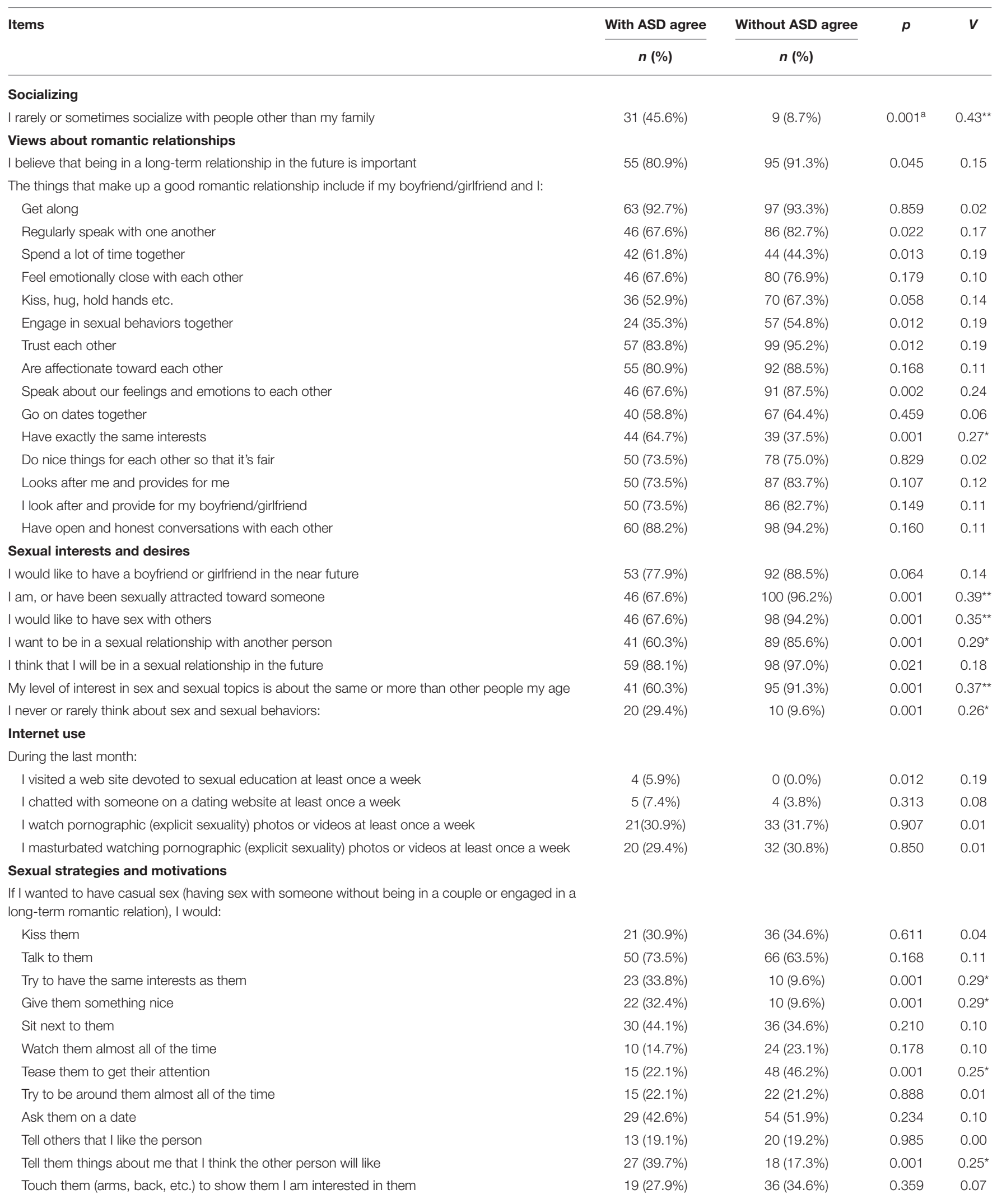


TABLE 1 | Continued

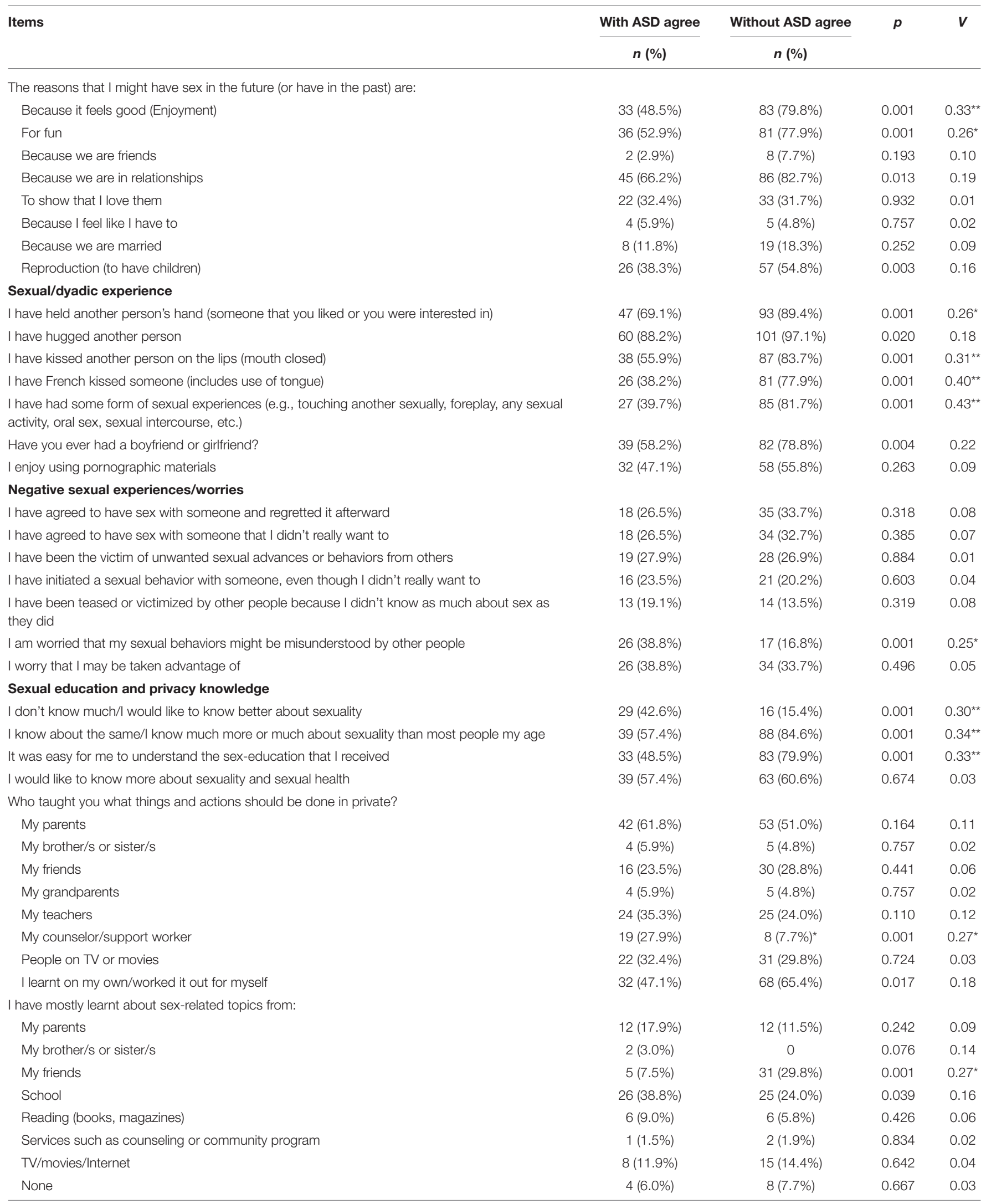


TABLE 1 | Continued

\begin{tabular}{|c|c|c|c|c|}
\hline Items & $\frac{\text { With ASD agree }}{n(\%)}$ & $\frac{\text { Without ASD agree }}{n(\%)}$ & $p$ & $\boldsymbol{v}$ \\
\hline \multicolumn{5}{|l|}{ I have been taught the importance of } \\
\hline Having tests for sexually-transmitted infections (STI's) & $60(88.2 \%)$ & $96(92.3 \%)$ & 0.369 & 0.07 \\
\hline Not making important decisions about sexual activities while affected by alcohol or drugs & $57(83.8 \%)$ & $91(87.5 \%)$ & 0.496 & 0.05 \\
\hline Touching someone in a sexual way & $63(92.6 \%)$ & $88(84.6 \%)$ & 0.116 & 0.12 \\
\hline Undressing the person & $66(97.1 \%)$ & $99(95.2 \%)$ & 0.545 & 0.05 \\
\hline Sexual behaviors (other than sexual intercourse) & $61(89.7 \%)$ & $92(88.5 \%)$ & 0.799 & 0.02 \\
\hline Sexual intercourse & $64(94.1 \%)$ & $93(89.4 \%)$ & 0.286 & 0.08 \\
\hline \multicolumn{5}{|l|}{ Sexual identity and orientation } \\
\hline I clearly identify myself as the gender that I was born (boy or girl) & $50(73.5 \%)$ & 99 (95.2\%) & 0.001 & $0.31^{\star \star}$ \\
\hline \multicolumn{5}{|l|}{ I consider my sexual orientation to be: } \\
\hline Bisexual (attracted to people of both sex) & $10(14.7 \%)$ & $20(19.2)$ & 0.445 & 0.06 \\
\hline Asexual (attracted to neither sex) & $4(6 \%)$ & $1(1.0 \%)$ & 0.060 & 0.14 \\
\hline Questioning (not sure who I am attracted to) & $5(7.4 \%)$ & $8(7.7 \%)$ & 0.934 & 0.01 \\
\hline
\end{tabular}

${ }^{1}$ Autistic Spectrum Disorder.

N/A, not applicable.

${ }^{a}$ The lowest possible $p$-value was set at 0.001 .

${ }^{b}$ Reported to be transgender or did not feel that assigned gender was correct.

*Near medium effect size (0.25-0.29).

${ }^{\star \star}$ Medium effect size (0.30 and over).

and 27 girls, mean age: $19.7 \pm 2.7$ ) and 104 without ASD (29 boys, mean age: $18.4 \pm 2.1$ and 75 girls, mean age: $19.1 \pm 2.6$; no significant difference in mean age between subgroups). No incentive was offered to participate in the study. Academic achievement varied, ranging from primary school (3\%), currently attending high school (39\%), having a high school diploma (35\%), and attending or having a college degree (23\%). All participants were French speaking Caucasians recruited in the province of Quebec (Canada). Using $\mathrm{G}^{*}$ Power (www.gpower.hhu.de), it was determined that 88 participants were necessary to achieve a statistical power of 0.80 based on an effect size of 0.30 and an alpha set at 0.05 . Given the high number of bivariate analyses included in this study (see below), that sample size target was doubled. All participants with ASD were recruited in clinical settings, community organizations and academic programs assisting adolescents with autism. They all received formal diagnoses of ASD without intellectual deficits by specialized mental health professionals based on the Diagnostic and Statistical Manual of Mental Disorders [4th ed., Text Revised, DSM; (69)], which included Autistic Disorder and Asperger's Syndrome. Diagnosis confirmation was obtained by self-report from participants.

\section{Material}

An online survey using REDCap was designed based on the Sexual Behavior Scale-Third edition (SBS-III) developed by Stokes and colleagues to evaluate sexual health of persons with
ASD $(2,30)$. The complete paper version of the questionnaire is available elsewhere (70). Following the approach of Pecora et al. (30) and Hancock et al. (2), items of the questionnaire were used individually, not in grouped domains. Given the main purpose of this study, only items related to sociodemographic information, sexuality, romantic relationships, and sexual education were used (see Tables 1-3 for all items retained). Because questions about inadequate or non-optimal social and sexual behaviors have been found to be non-valid in self-reports of adolescent/young adults with ASD [they are underestimated compared with parent reports or not well-understood by participants; (18, 71)], questions about inappropriate behaviors were not included in this study. It took $\sim 20 \mathrm{~min}$ on average to complete the survey.

\section{Statistical Analyses}

Following the approach of Hancock et al. (2) and Pecora et al. (30), a series of Chi Squares was first computed to compare responses of participants with and without ASD. Because this approach inflates the risk of Type I error, between-group significance was based solely on effect sizes (Cramer's $V$ ). The $p$ values were also calculated, but only for information purposes. Given the exploratory nature of this study (and its signaling function), large (>0.50), medium $(0.30-0.50)$ and near medium (0.25-0.29) effect sizes were considered as significant. Statistical power calculation (PASS software; www.ncss.com) revealed that a sample of 172 participants allowed to achieve a statistical 
power of 0.80 to detect an effect size of 0.26 using 1 degree of freedom Chi-Squares.

In a second step, simple logistic regressions were computed to evaluate the magnitude of variance explained by individual variables for two dichotomized dependent variables (DV: positive and negative sexual experience) related to participants with ASD. Given the number of participants with ASD $(n=68)$, six independent variables per DV were used (for a minimum of 10 participants per independent variable): Gender; age; age at first diagnosis for ASD; level of knowledge about sexuality and sexual behaviors (high level; answering yes to the question: "I know about the same as most people of my age about sexuality" or "I know much more than other people my age about sexuality"), level of socialization outside family (low level; answering yes to "I rarely socialize with people other than my family/I sometimes socialize with people other than my family") and; desire to have sex with others (yes). These simple logistic regressions were separately run for positive sexual experience (i.e., answering yes to the following question: "I have had some form of sexual experiences, e.g., touching another sexually, foreplay, any sexual activity, oral sex, sexual intercourse, etc.") and negative sexual experience (i.e., answering yes to any of the following questions: "I have agreed to have sex with someone and regretted it afterward"; "I have agreed to have sex with someone that I didn't really want to"; "I have been the victim of unwanted sexual advances or behaviors from others"; "I have initiated a sexual behavior with someone, even though I didn't really want to"). Finally, multivariate logistic regressions (enter method) were performed with significant independent variables for both positive and negative sexual experience $(p<0.05)$.

\section{Ethical Considerations}

This study was approved by the ethical committee of the Integrated University Health and Social Services Centre of Mauricie and Centre-du-Québec (to which the Intellectual Disability and Autism Spectrum Disorder Research Institute is affiliated).

\section{RESULTS}

\section{Socializing}

Significantly more participants with ASD (46.6\%) than TD participants $(8.7 \%)$ reported that they rarely or only sometimes socialize with people outside their family (Table 1). This finding was observed in both boys (43.9 vs. $10.3 \%$, respectively, Table 2 ) and girls (48.1 vs. $8 \%$, respectively, Table 3 ).

\section{Views About Romantic Relationships}

Much more similarities than differences were observed between the groups (ASD vs. TD) concerning their views about romantic relationships (Table 1). The notable exception was the significantly greater importance given by participants with ASD to have exactly the same interests with the other person to make up a good romantic relationship compared with their TD peers (64.7 vs. $37.5 \%$, respectively, Table $\mathbf{1}$ ).

\section{Sexual Interests and Desires}

Both groups wish to have a boyfriend/girlfriend in similar (not significantly different) proportions (ASD: $77.9 \%$ and TD: 82.7\%; Table 1). The majority of participants with ASD have been sexually attracted toward someone at least once (67.6\%), they wish to have sex with another person (67.6\%), and they want to be in a sexual relationship (60.3\%; Table 1). However, these rates were all significantly lower than those found in TD participants (96.2, 94.2, and $85.6 \%$, respectively; Table 1). These differences in rates of desire applied to boys (Table 2) and girls (Table 3), although the difference for wishing to have sex with another person did not reach statistical significance between girls. Similarly, a significantly lower proportion of participants with ASD felt that their interest in sex was equal or greater to their peers (60.3\%) compared with TD participants (91.3\%; Table 1). Accordingly, a significantly higher proportion of participants with ASD (29.4\%) than TD participants (9.6\%) reported they never or rarely think about sex (Table 1). These results applied to both boys (Table 2) and girls (Table 3).

\section{Pornography Consumption}

As for Internet pornography consumption, a significantly lower proportion of boys with ASD reported watching pornography (41.5 vs. $75.9 \%$, respectively) and/or masturbating with pornography (39 vs. $75.9 \%$, respectively) regularly (at least once a week) compared with those without ASD (Table 2). Among girls, rates of pornography consumption were much lower in both groups, without difference between them (Table 3 ).

\section{Sexual Strategies and Motivations}

Significant differences between participants with ASD vs. TD participants were found concerning strategies they would use to have casual sex. Whereas significantly higher proportions of the former group would act as a function of the other person (i.e., try to have similar interest as them and give them something nice), more TD participants stated that they would tease them to get attention (Table 1). These results held true for girls (Table 3) and partially for boys (only for trying to have same interests; Table 2). A significantly higher proportion of girls with ASD (39.7\%) compared to TD girls (17.3\%) also stated that they would tell things about themselves that they think the other person would like in order to have casual sex (Table 3).

Similarly, significantly fewer participants with than without ASD reported that they would have sex because it feels good (48.5 vs. $79.8 \%$, respectively) or for fun ( 52.9 vs. $77.9 \%$, respectively; Table 1). These results were confirmed for both boys (Table 2) and girls (Table 3).

\section{Sexual/Dyadic Experiences}

Significantly lower proportions of participants with ASD had experience with a variety of sexual/dyadic behaviors (Table 1). However, these differences mostly concerned boys (Table 2), as no difference was found between girls with and without ASD except for sexual experience (oral sex, sexual intercourse, etc.; Table 3). For instance, although a significantly lower percentage of boys with (42.5\%) than without (69\%) ASD ever had a girlfriend/boyfriend (Table 2), no difference emerged between 
TABLE 2 | Prevalence and inter-group comparisons of male adolescents/young adults with $(n=41)$ and without $(n=29)$ a diagnosis of ASD ${ }^{1}$.

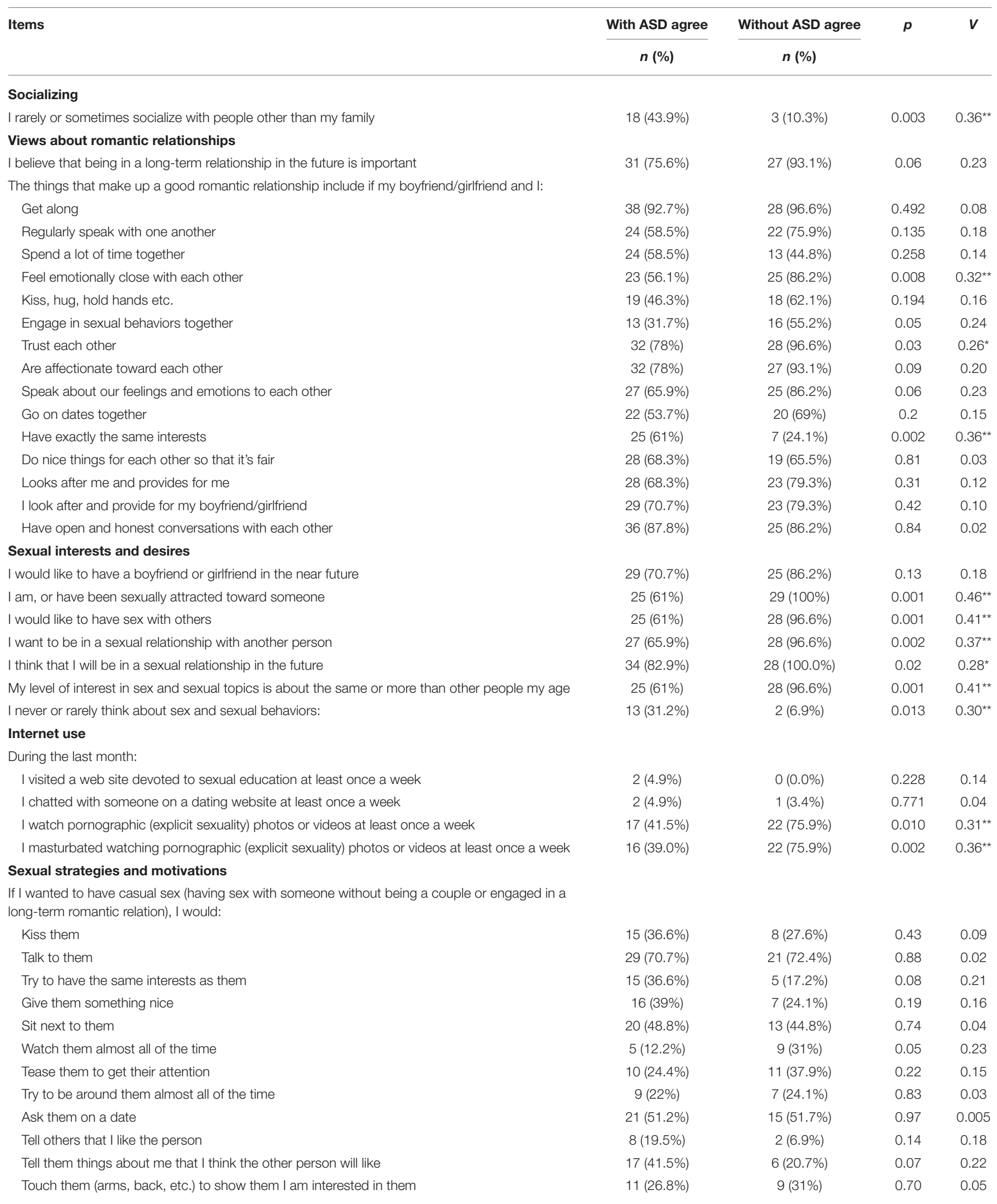


TABLE 2 | Continued

Items
The reasons that I might have sex in the
Because it feels good (Enjoyment)
For fun
Because we are friends
Because we are in relationships
To show that I love them
Because I feel like I have to
Because we are married
Reproduction (to have children)

\section{Sexual/dyadic experience}

I have held another person's hand (someone that you liked or you were interested in)

I have hugged another person

I have kissed another person on the lips (mouth closed)

I have French kissed someone (includes use of tongue)

I have had some form of sexual experiences (e.g., touching another sexually, foreplay, any sexual activity, oral sex, sexual intercourse, etc.)

Have you ever had a boyfriend or girlfriend?

I enjoy using pornographic materials

\section{Negative sexual experiences/worries}

I have agreed to have sex with someone and regretted it afterward

I have agreed to have sex with someone that I didn't really want to

I have been the victim of unwanted sexual advances or behaviors from others

I have initiated a sexual behavior with someone, even though I didn't really want to

I have been teased or victimized by other people because I didn't know as much about sex as they did

I am worried that my sexual behaviors might be misunderstood by other people

I worry that I may be taken advantage of

\section{Sexual education}

I don't know much/I would like to know better about sexuality

I know about the same/l know much more or much about sexuality than most people my age

It was easy for me to understand the sex-education that I received

I would like to know more about sexuality and sexual health

Who taught you what things and actions should be done in private?

My parents

My brother/s or sister/s

My friends

My grandparents

My teachers

My counselor/support worker

People on TV or movies

I learnt on my own/worked it out for myself

I have mostly learnt about sex-related topics from:

My parents

My brother/s or sister/s

My friends

School

Reading (books, magazines)

Services such as counseling or community program

TV/movies/Internet

None

With ASD agree

n (\%)

$21(51.2 \%)$
$24(58.5 \%)$
$2(4.9 \%)$
$27(65.9 \%)$
$14(34.1 \%)$
$2(4.9 \%)$
$7(17.1 \%)$
$20(48.8 \%)$

22 (53.7\%)

$33(80.5 \%)$

17 (41.5\%)

9 (22\%)

11 (26.8\%)

17 (42.5\%)

20 (48.8\%)

5 (12.2\%)

5 (12.2\%)

5 (12.2\%)

5 (12.2\%)

$6(14.6 \%)$

18 (43.9\%)

$13(31.7 \%)$

$18(43.9 \%)$

$23(56.1 \%)$

24 (58.5\%)

25 (61\%)

28 (68.3\%)

$1(2.4 \%)$

$11(26.8 \%)$

4 (9.8\%)

$13(31.7 \%)$

$13(31.7 \%)$

$12(29.3 \%)$

17 (41.5\%)

8 (20\%)

$1(2.4 \%)$

1 (2.5\%)

$18(45 \%)$

$3(7.5 \%)$

$13(31.7 \%)$

5 (12.5\%)

$3(7.5 \%)$
22 (75.9\%)

23 (79.3\%)

2 (6.9\%)

$23(79.3 \%)$

$10(34.5 \%)$

2 (6.9\%)

$4(13.8 \%)$

$18(62.1 \%)$

25 (86.2\%)

28 (96.6\%)

20 (69\%)

$19(65.5 \%)$

$21(72.4 \%)$

20 (69\%)

$22(75.9 \%)$

$6(14.6 \%)$

3 (10.3\%)

4 (13.8\%)

2 (6.9\%)

3 (10.3\%)

6 (21.4\%)

3 (10.7\%)

2 (6.9\%)

27 (93.1\%)

$24(82.8 \%)$

$22(75.9 \%)$

11 (37.9\%)

2 (6.9\%)

5 (17.2\%)

1 (3.4\%)

7 (24.1\%)

2 (2.9\%)

7 (24.1\%)

$24(82.8 \%)$

$4(13.8 \%)$

$0(0 \%)$

$5(17.2 \%)$

8 (27.6\%)

$2(6.9 \%)$

2 (2.9\%)

$4(13.8 \%)$

$4(13.8 \%)$
0.037

0.07

0.72

0.22

0.98

0.72

0.71

0.27

0.004

0.048

0.023

0.001

0.001

$0.03 \quad 0.26^{\star}$

$0.023 \quad 0.27^{\star}$

$0.768 \quad 0.035$

$0.811 \quad 0.03$

$0.844 \quad 0.02$

$0.467 \quad 0.09$

$0.597 \quad 0.06$

$0.05 \quad 0.23$

$0.04 \quad 0.24$

$0.02 \quad 0.40^{\star *}$

$0.001 \quad 0.35^{\star *}$

$0.0320 .26^{\star}$

$0.19 \quad 0.16$

$0.010 .30^{\star \star}$

$0.36 \quad 0.11$

$0.35 \quad 0.11$

$0.31 \quad 0.12$

$0.49 \quad 0.08$

$0.01 \quad 0.30^{\star \star}$

$0.63 \quad 0.06$

$0.001 \quad 0.41^{* *}$

$0.50 \quad 0.08$

$0.39 \quad 0.10$

$0.03 \quad 0.26^{\star}$

$0.14 \quad 0.18$

$0.92 \quad 0.01$

$0.24 \quad 0.14$

$0.88 \quad 0.02$

$0.393 \quad 0.10$ 
TABLE 2 | Continued

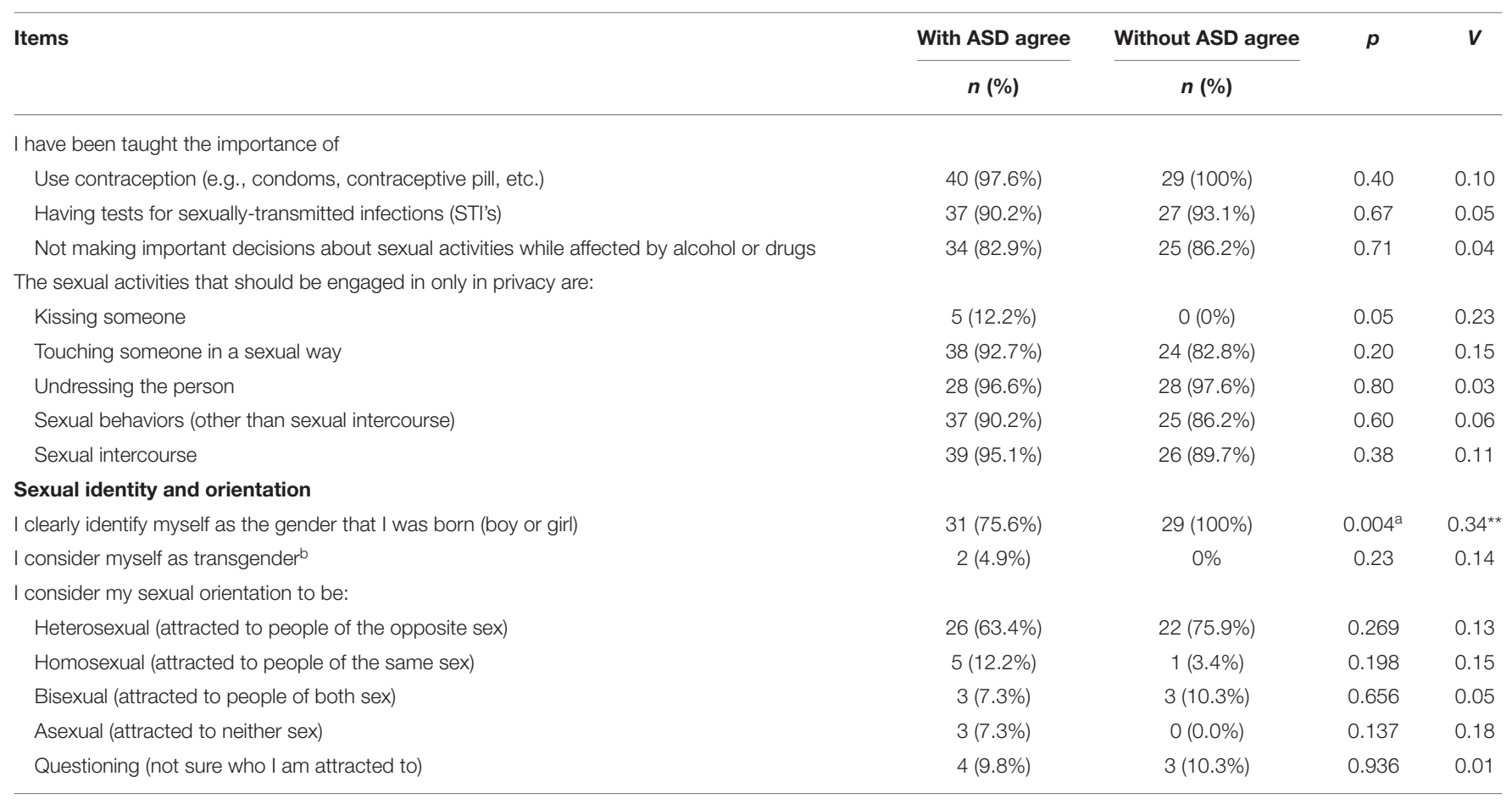

${ }^{1}$ Autistic Spectrum Disorder.

N/A, not applicable.

a The lowest possible $p$-value was set at 0.001 .

${ }^{b}$ Reported to be transgender or did not feel that assigned gender was correct.

${ }^{\star}$ Near medium effect size (0.25-0.29).

${ }^{* \star M e d i u m}$ effect size (0.30 and over).

the groups of girls (Table 3). In fact, a higher percentage of girls with ASD (81.5\%) than boys without ASD (69\%) reported having had a boyfriend/girlfriend at least once in their lifetime.

\section{Negative Sexual Experience/Worries}

No significant difference emerged between the groups (participants with vs. without ASD) for rates of negative sexual experiences (Table 1). However, much higher proportions of girls overall reported negative sexual experiences (between 25.3 and $51.9 \%$, Table 3 ) compared with boys (between 7 and $14.6 \%$, Table 2). The proportion of girls reporting unwanted sexual advances or behaviors from others was higher among those with ASD (51.9\%) than among TD girls (32\%), although the difference did not reach statistical significance. These results might reflect the high base rate of sexual victimization among girls in general, a lack of statistical power or both. More participants with ASD also worried that their sexual behaviors might be misunderstood by other people compared with their TD peers (38.8 vs. $16.8 \%$, respectively, Table 1 ).

\section{Sexual Education and Knowledge}

Significantly higher rates of participants with ASD felt they did not know much about sexuality $(42.6 \%)$ than TD participants (15.4\%; Table 1). Therefore, significantly more TD participants considered they know as much or more about sexuality than their peers $(84.6 \%)$ compared with participants with ASD
(57.4\%; Table 1). In addition, a significantly lower proportion of participants with ASD (48.5\%) found it easy to understand sex education compared with TD participants (79.9\%; Table 1). However, the majority of both groups expressed wishes to know more about sexuality (no significant difference between the groups; Table 1). These results held for boys (Table 2) and partially for girls (Table 3 ). As expected, sexual education and advice was more likely to be given by counselors and less likely by friends to participants with ASD compared with their TD peers (Table 1). These results only concerned boys, however, as no difference emerged between groups of girls (Table 3). In fact, boys with ASD were more likely to have received sexual education or advice by their parents or counselors, and less likely to receive it from friends or by themselves than boys without ASD (Table 2).

Information about contraception, sexually-transmitted infections, and usage of alcohol/drugs seem to have been adequately provided in both groups (Table 1). Similarly, no significant difference emerged between participants with ASD and TD participants concerning their knowledge of behaviors requiring privacy (Tables $\mathbf{1}-\mathbf{3}$ ).

\section{Sexual Identity and Orientation}

Significantly lower rates of participants with ASD (73.5\%) reported that they identify as their assigned gender 
TABLE 3 | Prevalence and inter-group comparisons of female adolescents/young adults with $(n=27)$ and without $(n=75)$ a diagnosis of ASD ${ }^{1}$.

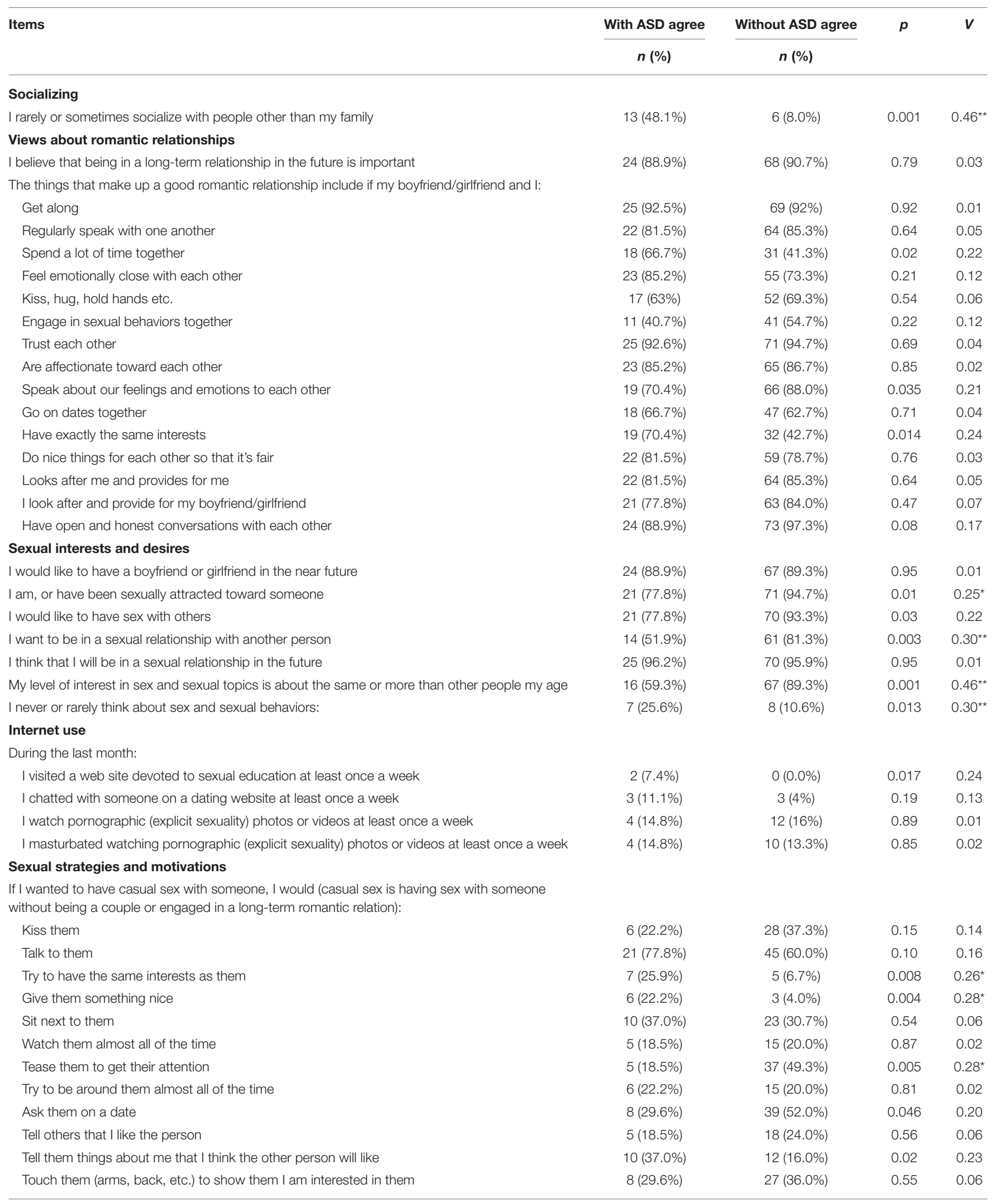


TABLE 3 | Continued

Items
The reasons that I might have sex in the
Because it feels good (Enjoyment)
For fun
Because we are friends
Because we are in relationships
To show that I love them
Because I feel like I have to
Because we are married
Reproduction (to have children)

\section{Sexual/dyadic experience}

I have held another person's hand (someone that you liked or you were interested in)

I have hugged another person

I have kissed another person on the lips (mouth closed)

I have French kissed someone (includes use of tongue)

I have had some form of sexual experiences (e.g., touching another sexually, foreplay, any sexual activity, oral sex, sexual intercourse, etc.)

Have you ever had a boyfriend or girlfriend?

I enjoy using pornographic materials

\section{Negative sexual experiences/worries}

I have agreed to have sex with someone and regretted it afterward

I have agreed to have sex with someone that I didn't really want to

I have been the victim of unwanted sexual advances or behaviors from others

I have initiated a sexual behavior with someone, even though I didn't really want to

I have been teased or victimized by other people because I didn't know as much about sex as they did

I am worried that my sexual behaviors might be misunderstood by other people

I worry that I may be taken advantage of

\section{Sexual education}

I don't know much/I would like to know better about sexuality

I know about the same/l know much more or much about sexuality than most people my age

It was easy for me to understand the sex-education that I received

I would like to know more about sexuality and sexual health

Who taught you what things and actions should be done in private?

My parents

My brother/s or sister/s

My friends

My grandparents

My teachers

My counselor/support worker

People on TV or movies

I learnt on my own/worked it out for myself

I have mostly learnt about sex-related topics from:

My parents

My brother/s or sister/s

My friends

School

Reading (books, magazines)

Services such as counseling or community program

TV/movies/Internet

None
With ASD agree

n (\%)

Without ASD agree

p v

n (\%)

$12(44.4 \%)$
$12(44.4 \%)$
$0(0 \%)$
$18(66.7 \%)$
$8(29.6 \%)$
$2(7.4 \%)$
$1(3.7 \%)$
$6(22.2 \%)$

$25(92.6 \%)$

27 (100\%)

$21(77.8 \%)$

$16(63 \%)$

$16(59.3 \%)$

$22(81.5 \%)$

$12(44.4 \%)$

$12(44.4 \%)$

$13(48.1 \%)$

$14(51.9 \%)$

$11(40.7 \%)$

7 (25.9\%)

$8(30.8 \%)$

$13(50.0 \%)$

$11(40.7 \%)$

27 (59.3\%)

9 (33.3\%)

$14(51.9 \%)$

14 (51.9\%)

$3(11.1 \%)$

5 (18.5\%)

$0(0.0 \%)$

$11(40.7 \%)$

$6(22.2 \%)$

$10(37.0 \%)$

15 (55.6\%)

$4(14.8 \%)$

1 (3.7\%)

$4(14.8 \%)$

8 (29.6\%)

3 (11.1\%)

1 (3.7\%)

3 (11.1\%)

1 (3.7\%)

$$
\begin{aligned}
& 61 \\
& 58 \\
& 63 \\
& 23 \\
& 3 \\
& 15 \\
& 39
\end{aligned}
$$

58 (77.3\%)

$6(8 \%)$

63 (84\%)

23 (30.7\%)

$3(4.0 \%)$

15 (20\%)

39 (52.0\%)

$68(90.7 \%)$

$73(97.3 \%)$

67 (89.3\%)

$62(82.7 \%)$

$64(85.3 \%)$

$62(82.7 \%)$

36 (48\%)

30 (40\%)

$31(41.3 \%)$

24 (32\%)

$19(25.3 \%)$

$11(14.7 \%)$

$11(15.1 \%)$

31 (42.5\%)

$14(18.7 \%)$

$61(81.3 \%)$

$59(78.7 \%)$

$41(54.7 \%)$

42 (56.0\%)

$3(4.0 \%)$

25 (33.3\%)

$4(5.3 \%)$

18 (24.0\%)

$6(8.0 \%)$

$24(32.0 \%)$

44 (58.7\%)

$8(10.7 \%)$

$0(0 \%)$

26 (34.7\%)

$17(22.7 \%)$

$4(5.3 \%)$

$1(1.3 \%)$

$11(14.7 \%)$

$4(5.3 \%)$
$0.0010 .36^{\star \star}$

$0.002 \quad 0.31^{* *}$

$0.13 \quad 0.15$

$0.056 \quad 0.19$

$0.92 \quad 0.01$

$0.48 \quad 0.07$

$0.046 \quad 0.20$

$0.008 \quad 0.27^{\star}$

$0.76 \quad 0.03$

$0.39 \quad 0.09$

$0.14 \quad 0.15$

$0.04 \quad 0.21$

$0.0050 .28^{\star}$

$0.89 \quad 0.01$

$0.75 \quad 0.03$

$0.69 \quad 0.04$

$0.54 \quad 0.06$

$0.07 \quad 0.18$

$0.13 \quad 0.15$

$0.19 \quad 0.13$

$0.08 \quad 0.18$

$0.51 \quad 0.07$

$0.02 \quad 0.23$

$0.04 \quad 0.22$

$0.000 \quad 0.42^{*}$

$0.80 \quad 0.03$

$0.71 \quad 0.04$

$0.18 \quad 0.13$

$0.15 \quad 0.14$

$0.22 \quad 0.12$

$0.10 \quad 0.16$

$0.049 \quad 0.19$

$0.63 \quad 0.05$

$0.78 \quad 0.03$

$0.57 \quad 0.06$

$0.09 \quad 0.17$

$0.05 \quad 0.19$

$0.47 \quad 0.07$

$0.31 \quad 0.10$

$0.47 \quad 0.08$

$0.65 \quad 0.05$

$0.74 \quad 0.03$

(Continued) 


\begin{tabular}{|c|c|c|c|c|}
\hline Items & $n(\%)$ & $n(\%)$ & & \\
\hline \multicolumn{5}{|l|}{ I have been taught the importance of: } \\
\hline Use contraception (e.g., condoms, contraceptive pill, etc.) & $26(96.3 \%)$ & $75(100.0 \%)$ & 0.09 & 0.17 \\
\hline Having tests for sexually-transmitted infections (STI's) & $23(85.2 \%)$ & $69(92.0 \%)$ & 0.31 & 0.10 \\
\hline Kissing someone & $3(11.1 \%)$ & $2(2.7 \%)$ & 0.08 & 0.17 \\
\hline Touching someone in a sexual way & $25(92.6 \%)$ & $64(85.3 \%)$ & 0.33 & 0.10 \\
\hline Undressing the person & 26 (96.3\%) & 71 (94.7\%) & 0.77 & 0.03 \\
\hline Sexual behaviors (other than sexual intercourse) & $24(88.9 \%)$ & $67(89.3 \%)$ & 0.95 & 0.006 \\
\hline Sexual intercourse & $25(92.6 \%)$ & $67(89.3 \%)$ & 0.63 & 0.05 \\
\hline \multicolumn{5}{|l|}{ I consider my sexual orientation to be: } \\
\hline Heterosexual (attracted to people of the opposite sex) & $17(63.0 \%)$ & $52(69.3 \%)$ & 0.54 & 0.06 \\
\hline Homosexual (attracted to people of the same sex) & $1(3.7 \%)$ & $0(0.0 \%)$ & 0.09 & 0.17 \\
\hline Bisexual (attracted to people of both sex) & $5(27.9 \%)$ & $17(22.7 \%)$ & 0.73 & 0.03 \\
\hline Asexual (attracted to neither sex) & 1 (3.7\%) & $1(1.3 \%)$ & 0.45 & 0.08 \\
\hline Questioning (not sure who I am attracted to) & $1(3.7 \%)$ & $5(6.7 \%)$ & 0.58 & 0.06 \\
\hline
\end{tabular}

${ }^{1}$ Autistic Spectrum Disorder.

N/A, not applicable.

${ }^{a}$ The lowest possible $p$-value was set at 0.001 .

${ }^{b}$ Reported to be transgender or did not feel that assigned gender was correct.

${ }^{\star}$ Near medium effect size (0.25-0.29).

${ }^{\star *}$ Medium effect size ( 0.30 and over).

compared with TD participants (95.2\%, Table 1). This finding was true for both males (73.5 vs. 100\%, respectively, Table 2) and females (70.4 vs. 93.3\%, respectively, Table 3). However, no significant differences emerged between the groups for rates of any sexual orientation (Table 1). This finding was also true for both males (Table 2) and females (Table 3).

\section{Predictions of Positive and Negative Sexuality}

Gender [female; Wald $=6.8, p=0.009$, $\operatorname{Exp}(B)=4.0$, C.I.: 1.4-11.1], age at first diagnosis for ASD [older; Wald $=6.2$, $p=0.01, \operatorname{Exp}(\mathrm{B})=1.1$, C.I.: 1.03-1.2], self-reported level of knowledge about sexuality and sexual behaviors [higher; Wald $=4.9, p=0.03, \operatorname{Exp}(B)=3.3$, C.I.: 1.2-9.5], and desire to have sex with others [yes; Wald $=7.9, p=0.005, \operatorname{Exp}(B)=6.9$, C.I.: 1.8-26.6] were all significant single predictors of having positive sexual experience among participants with ASD. Thus, current age and extra-familial sociability were not associated with the odds of having positive sexual experience among persons with ASD. Unexpectedly, the exact same variables were also significant predictors of having negative sexual experience among participants with ASD: Being a girl [Wald $=6.8, p=0.009$, $\operatorname{Exp}(B)=4.0$, C.I.: 1.4-11.1], being older at first diagnosis of ASD [Wald $=8.0, p=0.005, \operatorname{Exp}(B)=1.2$, C.I.: $1.0-$ $1.3]$, considered as having good knowledge about sexuality and sexual behaviors $[\operatorname{Exp}(B)=4.5, p=0.007$, C.I.: 1.5-13.4], and desiring having sex with others [Wald $=5.7, p=0.01$, $\operatorname{Exp}(B)=4.5$, C.I.: 1.3-15.3]. Current age and extra-familial sociability were not associated with the odds of having negative sexual experience. Multivariate logistic regressions conducted with these four significant variables indicated that two of them contributed significantly and independently to the variance of having positive sexual experience: older age at first diagnosis for ASD and better knowledge about sexuality and sexual behaviors. Together, these two variables explained approximately a fifth of the variance (22\%) and correctly classified $72 \%$ of the sample $\left(R^{2}=0.223\right)$. Again, the same two variables significantly and independently predicted the presence of negative sexual experience, explaining approximately a third of the variance and correctly classified $73.4 \%$ of the sample $\left(R^{2}=0.353\right)$. To obtain the most parsimonious regression models possible, independent variables that did not significantly contribute to the explanation of the dependent variables were excluded. Although more contingent upon a specific sample, this procedure allows for the reduction of the number of variables in the model and results in a more statistically stable model (72). After gender and desire to have dyadic sex were excluded from analyses, final logistic regressions were conducted for both positive and negative sexual experiences. The interaction effects were determined for each of the models but were not retained in the final analysis, as none were significant. 
These unexpected findings that positive and negative sexual experience were predicted by the same variables might reflect at least two possibilities: (1) Participants with ASD who have positive sexual experience also tend to have negative sexual experience; (2) Participants with ASD interpreted questions meant to assess positive sexual experience (i.e., the dependent variable: "I have had some form of sexual experiences, e.g., touching another sexually, kissing, foreplay, any sexual activity, oral sex, sexual intercourse, etc.") as questions related to any sexual experience (i.e., unwanted oral sex). In order to assess these two alternatives, rates of positive vs. negative sexual experience were compared between and within groups. Among TD participants, $81.7 \%(n=85)$ had at least one positive sexual experience and $53.8 \%(n=56)$ had at least one negative sexual experience, with $36.5 \%(n=31)$ reporting only positive experience. Among participants with ASD, 39.7\% $(n=27)$ reported at least one positive sexual experience but 39.7\% ( $n=$ 27) also reported at least one negative sexual experience, with only $18.5 \%(n=5)$ reporting only positive sexual experience (another 5 participants reported only negative sexual experience). Therefore, adolescents/young adults with any sexual experience tended to report some negative sexual experience, especially among those with ASD.

\section{DISCUSSION}

The main goal of this exploratory study was to ask adolescents/young adults with ASD about their sexual knowledge, desire and experience. A second study goal was to compare their responses to those of TD peers. The third goal was to compare results between boys and girls in both groups. A final objective was to assess the predictive value of selected variables on positive and negative sexual experience among participants with ASD.

As expected, the majority of our participants expressed the desire to have romantic/sexual relationships. Still, it is also worth noting that significant proportions of adolescents/young adults with ASD reported low or no interest in sexual relationships, among both boys and girls. These results illustrate the heterogeneity of the group and the fact that some persons with ASD, at least when young adults, are simply not interested in socio-sexual behaviors. Even weekly rates of watching pornography and masturbating were lower in boys with ASD in this study. Compared with TD participants, adolescents/young adults with ASD also reported less sexual knowledge and experience. For instance, higher proportions of boys and girls with ASD felt that trying to have common interests with another person or giving that person something nice were good strategies to have casual sex with them. Furthermore, fewer participants with ASD had experience with actual sexual behaviors (e.g., oral sex, intercourse). These results stress the importance of providing adequate and adapted sexual education to adolescents/young adults with (and without) ASD. First, adolescents with ASD receive less sexual information from their friends compared with TD adolescents. Although biological aspects of sexuality seem to be well-understood (e.g., contraception, STI), socio-sexual education is needed. In fact, most participants in this study, with or without ASD, wished to learn more about sexuality. Second, however, more sexual knowledge is also associated with higher risk to be sexually victimized in young persons with ASD. Therefore, socio-sexual education should go beyond physical aspects of sexuality and encompass such notions as intimacy, self-respect, self-esteem, mutual consent, understanding intentions of others, and verbal and non-verbal romantic communication.

Knowledge about romantic relationships (e.g., things that make up a good relationship) and privacy was generally considered as good by participants in this study, contrary to what is typically reported by parents or among adults with ASD $(13,15)$. Similar conclusions were drawn from two other selfreport studies of adolescents with $\operatorname{ASD}(18,23)$. These results might reflect the influence of using self-reports (instead of parent or caregiver reports), better social services offered to youngsters with ASD nowadays, a better access to information through Internet, or a mix of these factors.

Interestingly, substantial differences emerged between boys and girls with ASD in this study, reflecting the importance of considering both genders separately in the sexual investigation of persons with ASD. As in previous studies of adults (10, 38), girls with ASD reported better knowledge and experience with romantic/sexual relationships than boys. Despite better knowledge, girls were also much more likely to report past negative sexual experiences than boys, although these results applied to all girls (with or without ASD). The rate of girls with ASD reporting negative sexual experience was alarmingly high in this study (51.9\%), yet somewhat lower than that found by Pecora et al. [(30); from 60 to $78.2 \%$ for women with ASD depending on specific items].

Also noteworthy is the fact that significantly lower rates of participants with ASD, both among boys and among girls, clearly identified themselves with their birth gender compared with TD participants, extending data obtained with adults $(26,27)$. This gender diversity might reflect psychological (e.g., greater openness) and/or neurological factors. For instance, prenatal androgens are believed to masculinize the brain and a negative association exists between intrauterine exposition to testosterone (high) and the 2:4 digit (major and auricular fingers) ratio [low; (73)]. Given that persons with ASD have, on average, lower 2:4 digit ratios $(74,75)$, and that higher steroidogenic activity is found in amniotic fluid during pregnancy leading to boys with $\operatorname{ASD}(76,77)$, high levels of androgens in utero are hypothesized to contribute to ASD (76). Although that hypothesis remains controversial [e.g., (78)], it might be associated with the intriguing link between ASD and gender dysphoria because rates of gender dysphoria or transgender are both significantly higher among persons with ASD and linked to lower 2:4 digit ratios $(79,80)$. Future neurobiological studies of ASD should further explore these avenues.

As for sexual orientation, rates of homosexuality or bisexuality did not differ between ASD vs. non-ASD groups in the present study, contrary to what is usually reported in adults with ASD $[(38,47,49-51,54)$; see $(26,27)$ for reviews]. It should be noted, however, that base rates of non-heterosexuality were significantly 
higher in the TD group, both for boys and girls (between 25 and $30 \%)$ than among the general population of adults in Canada [between 1 and 3\%; (81)]. This result might reflect the relatively low age of participants in this study and the high proportions still unsure of (or more open about) their sexual orientation in both groups.

As expected, being female, being older at first diagnosis, having a better knowledge about sexuality and sexual behaviors, and desiring to have sex with others were all significant predictors of having positive sexual experience among participants with ASD. What was less expected, however, was the fact that the same variables were also significant predictors of negative sexual experience, especially for having a better sexual knowledge. Being older at first diagnosis of ASD and having better sexual knowledge might be related with better capacities to mask (or camouflage) difficulties in social interaction and communication, particularly among girls $(82,83)$. These characteristics, paired with a desire to have sex with others (this study), a strong need to be liked by peers and better mimicking and vocabulary capacities [e.g., (84)], might put these girls at higher risks to be misinterpreted, exploited, and/or sexually abused (40). Future investigations should test this possible link between symptom masking and negative sexual experience.

Finally, some limitations of this study should be noted before generalizing these results. First, dividing study groups by genders significantly lowered the statistical power in this study. Further confirmatory studies with larger groups of male and female participants and higher statistical power are warranted. Second, the diagnoses of ASD were not confirmed with a screening tool [e.g., AQ, (85)] in this study. Although all participants with ASD received an official diagnosis confirmed with self-report, it remains possible that some of them would not have met the cut-off of a screening instrument. In opposition, some participants of the control group might have presented autistic traits. Third, although the questionnaire (SBS-III) has been statistically validated (70), its face validity was not assessed and some questions related to sexuality might have been difficult to understand for certain participants. For instance, although some questions about sexual experience were aimed at documenting positive sexuality ("I have had some form of sexual experiences, e.g., touching another sexually, kissing, foreplay, any sexual activity, oral sex, sexual intercourse, etc.), they might have been interpreted as comprising any sexual experience, including non-consenting behaviors. Therefore, the definition of positive sexuality in this study might in fact have included negative experience. Clearly, further validation studies are required with the SBSIII, including pilot testing involving feedback and suggestions from young persons with ASD. Finally, all items of the questionnaire were dichotomized (e.g., yes-no) for statistical analyses so that nuance and some information were lost in the process.

Overall, results from this study confirm that most adolescents/young adults with ASD wish to be in a romantic and/or sexual relationship, although a significant minority report lower or no interest for sex. Girls with ASD have more romantic and sexual experience than boys with ASD. However, the rate of negative sexual experience was particularly high among girls with ASD, associated with a later age of diagnosis and better sexual knowledge. It is possible that better capacities to mask difficulties in social interactions and communication, paired with a need to be liked and a desire to be in a romantic/sexual relationship represent risk factors for sexual victimization of young adults with ASD. Sexual education should not only be provided to adolescents with and without ASD, it should also include socio-sexual notions to prevent this type of victimization and promote a healthy sexual life.

\section{DATA AVAILABILITY STATEMENT}

The raw data supporting the conclusions of this article will be made available by the authors, without undue reservation.

\section{ETHICS STATEMENT}

The studies involving human participants were reviewed and approved by Integrated University Health and Social Services Centre of Mauricie and Centre-du-Québec. Written informed consent to participate in this study was provided by the participants' legal guardian/next of kin.

\section{AUTHOR CONTRIBUTIONS}

CCJ, JC, SM, CN, and M-HP designed the study, adapted the instrument, and collected the data. M-HP supervised the recruitment of participants. CCJ, JC, and SM conducted statistical analyses. CCJ wrote the first draft of the manuscript. JC, SM, CN, and M-HP revised the manuscript. All authors contributed to the article and approved the submitted version.

\section{FUNDING}

This study was supported by a partnership research grant (Concerted Action Program; M-HP, principal investigator) from the Fonds de Recherche du Québec-Société et Culture (FQRSC; No 2019-SA-264334), the National Network of Experts in Autism Spectrum Disorder and the Ministry of Education and Higher Education. CCJ also received a research grant from the Office des personnes handicapées du Québec (OPHQ; Ref. 2231).

\section{ACKNOWLEDGMENTS}

We are very grateful to all adolescents and young adults who took part in this study, as well as the counselors, teachers, health care providers, and parents who referred them to us. 


\section{REFERENCES}

1. Hancock GI, Stokes MA, Mesibov GB. Socio-sexual functioning in autism spectrum disorder: a systematic review and meta-analyses of existing literature. Autism Res. (2017) 10:1823-33. doi: 10.1002/aur. 1831

2. Hancock GI, Stokes MA, Mesibov G. Differences in romantic relationship experiences for individuals with an Autism Spectrum Disorder. Sex Disabil. (2019) 38:231-45. doi: 10.1007/s11195-019-0 9573-8

3. Mehzabin P, Stokes MA. Self-assessed sexuality in young adults with high-functioning autism. Res Autism Spectr Disord. (2011) 5:614-21. doi: 10.1016/j.rasd.2010.07.006

4. Sawyer SM, Azzopardi PS, Wickremarathne D, Patton GC. The age of adolescence. Lancet Child Adolesc Health. (2018) 2:223-8. doi: 10.1016/S2352-4642(18)30022-1

5. Kar SK, Choudhury A, Singh AP. Understanding normal development of adolescent sexuality: a bumpy ride. J Hum Reproduct Sci. (2015) 8:704. doi: 10.4103/0974-1208.158594

6. Tulloch T, Kaufman M. Adolescent sexuality. Pediatr Rev. (2013) 34:2937. doi: 10.1002/9780470479193.adlpsy001015

7. Bennett AE, Miller JS, Stollon N, Prasad R, Blum NJ. Autism spectrum disorder and transition-aged youth. Curr Psychiatry Rep. (2018) 20:103. doi: 10.1007/s11920-018-0967-y

8. Elgar S. Sex education and sexual awareness building for autistic children and youth: some viewpoints and considerations. J Autism Dev Disord. (1985) 15:214-6.

9. Strunz S, Schermuck C, Ballerstein S, Ahlers CJ, Dziobek I, Roepke S. Romantic relationships and relationship satisfaction among adults with Asperger syndrome and high-functioning autism. J Clin Psychol. (2017) 73:113-25. doi: 10.1002/jclp.22319

10. Pecora LA, Mesibov GB, Stokes MA. Sexuality in high-functioning autism: a systematic review and meta-analysis. J Autism Dev Disord. (2016) 46:351956. doi: 10.1007/s10803-016-2892-4

11. Dewey MA, Everard MP. The near-normal autistic adolescent. J Autism Child Schizophr. (1974) 4:348-56.

12. Fernandes LC, Gillberg CI, Cederlund M, Hagberg B, Gillberg C, Billstedt E. Aspects of sexuality in adolescents and adults diagnosed with autism spectrum disorders in childhood. J Autism Dev Disord. (2016) 46:315565. doi: 10.1007/s10803-016-2855-9

13. Ginevra MC, Nota L, Stokes M. The differential effects of Autism and Down's syndrome on sexual behavior. Autism Res. (2016) 9:13140. doi: 10.1002/aur.1504

14. Hellemans H, Colson K, Verbraeken C, Vermeiren R, Deboutte D. Sexual behavior in high-functioning male adolescents and young adults with autism spectrum disorder. J Autism Dev Disord. (2007) 37:2609. doi: 10.1007/s10803-006-0159-1

15. Stokes MA, Kaur A. High-functioning autism and sexuality: a parental perspective. Autism. (2005) 9:266-89. doi: 10.1177/1362361305053258

16. Stokes M, Newton N, Kaur A. Stalking, and social and romantic functioning among adolescents and adults with autism spectrum disorder. J Autism Dev Disord. (2007) 37:1969-86. doi: 10.1007/s10803-006-0344-2

17. Teti M, Cheak-Zamora N, Bauerband LA, Maurer-Batjer A. A qualitative comparison of caregiver and youth with autism perceptions of sexuality and relationship experiences. J Dev Behav Pediatr. (2019) 40:12-9. doi: 10.1097/DBP.0000000000000620

18. Dekker LP, van der Vegt EJ, van der Ende J, Tick N, Louwerse A, Maras A, et al. Psychosexual functioning of cognitively-able adolescents with autism spectrum disorder compared to typically developing peers: the development and testing of the teen transition inventory-a self-and parent report questionnaire on psychosexual functioning. J Autism Dev Disord. (2017) 47:1716-38. doi: 10.1007/s10803-017-3071-y

19. Dewinter J, Vermeiren R, Vanwesenbeeck I, Van Nieuwenhuizen. C. Parental awareness of sexual experience in adolescent boys with autism spectrum disorder. J Autism Dev Disord. (2016) 46:713-9. doi: 10.1007/s10803-015-2622-3

20. Hartmann K, Urbano MR, Raffaele CT, Qualls LR, Williams TV, Warren C, et al. Sexuality in the Autism Spectrum Study (SASS): reports from young adults and parents. J Autism Dev Disord. (2019) 49:363855. doi: 10.1007/s10803-019-04077-y

21. Dewinter J, van der Miesen AI, Holmes LG. INSAR special interest group report: stakeholder perspectives on priorities for future research on autism, sexuality, and intimate relationships. Autism Res. (2020) 13:124857. doi: 10.1002/aur.2340

22. Cheak-Zamora NC, Teti M, Maurer-Batjer A, O'Connor KV, Randolph JK. Sexual and relationship interest, knowledge, and experiences among adolescents and young adults with autism spectrum disorder. Archiv Sex Behav. (2019) 48:2605-15. doi: 10.1007/s10508-019-1445-2

23. Dewinter J, Vermeiren R, Vanwesenbeeck I, Lobbestael J, Van Nieuwenhuizen. C. Sexuality in adolescent boys with autism spectrum disorder: selfreported behaviours and attitudes. J Autism Dev Disord. (2015) 45:73141. doi: 10.1007/s10803-014-2226-3

24. Dewinter J, Vermeiren, R, Vanwesenbeeck I, Van Nieuwenhuizen. C. Adolescent boys with autism spectrum disorder growing up: follow-up of self-reported sexual experience. Eur Child Adolesc Psychiatry. (2016) 25:96978. doi: 10.1007/s00787-016-0816-7

25. Perneger TV. What's wrong with Bonferroni adjustments. Br Med J. (1998) 316:1236-8. doi: 10.1136/bmj.316.7139.1236

26. Pecora LA, Hooley M, Sperry L, Mesibov GB, Stokes MA. Sexuality and gender issues in individuals with autism spectrum disorder. Child Adolesc Psychiatry Clin N Am. (2020) 29:543-56. doi: 10.1016/j.chc.2020.02.007

27. Sala G, Pecora L, Hooley M, Stokes MA. As diverse as the spectrum itself: trends in sexuality, gender and autism. Curr Dev Disord Rep. (2020) 7:5968. doi: 10.1007/s40474-020-00190-1

28. Brown KR, Peña EV, Rankin S. Unwanted sexual contact: students with autism and other disabilities at greater risk. J Coll Stud Dev. (2017) 58:7716. doi: 10.1353/csd.2017.0059

29. Brown-Lavoie S, Viecili M, Weiss J. Sexual knowledge and victimization in adults with autism spectrum disorders. J Autism Dev Disord. (2014) 44:218596. doi: 10.1007/s10803-014-2093-y

30. Pecora LA, Hancock GI, Mesibov GB, Stokes MA. Characterising the sexuality and sexual experiences of autistic females. J Autism Dev Disord. (2019) 49:4834-46. doi: 10.1007/s10803-019-04204-9

31. Bush HH. Self-reported sexuality among women with and without autism spectrum disorder (ASD) (Order No. 10118389) (ProQuest Dissertations \& Theses Global) (1803936932) (2016). Retrieved from: https://www-proquestcom.biblioproxy.uqtr.ca/dissertations-theses/self-reported-sexualityamong-women-with- without/docview/1803936932/se-2?accountid=14725

32. Weiss JA, Fardella MA. Victimization and perpetration experiences of adults with autism. Front Psychiatry. (2018) 9:203. doi: 10.3389/fpsyt.2018.00203

33. Cridland EK, Jones SC, Caputi P, Magee CA. Being a girl in a boys' world: investigating the experiences of girls with autism spectrum disorders during adolescence. J Autism Dev Disord. (2014) 44:126174. doi: 10.1007/s10803-013-1985-6

34. Pecora LA, Hancock GI, Hooley M, Demmer DH, Attwood T, Mesibov GB, et al. Gender identity, sexual orientation and adverse sexual experiences in autistic females. Mol Autism. (2020) 11:57. doi: 10.1186/s13229-020-00363-0

35. Conroy S, Cotter A. Self-Reported Sexual Assault in Canada, 2014. Juristat, Statistics Canada Catalogue no. 85-002-X. Statistics Canada (2017).

36. Ohlsson Gotby V, Lichtenstein P, Långström N, Pettersson E. Childhood neurodevelopmental disorders and risk of coercive sexual victimization in childhood and adolescence-a population-based prospective twin study. $J$ Child Psychol Psychiatry. (2018) 59:957-65. doi: 10.1111/jcpp.12884

37. Roberts AL, Koenen KC, Lyall K, Robinson EB, Weisskopf MG. Association of autistic traits in adulthood with childhood abuse, interpersonal victimization, and posttraumatic stress. Child Abuse Neglect. (2015) 45:135-142. doi: 10.1016/j.chiabu.2015.04.010

38. Byers ES, Nichols S, Voyer SD, Reilly G. Sexual well-being of a community sample of high-functioning adults on the autism spectrum who have been in a romantic relationship. Autism. (2013) 17:41833. doi: $10.1177 / 1362361311431950$

39. Hull L, Petrides KV, Mandy W. The female autism phenotype and camouflaging: a narrative review. Rev J Autism Dev Disord. (2020) 7:30617. doi: 10.1007/s40489-020-00197-9

40. Bargiela S, Steward R, Mandy W. The experiences of latediagnosed women with autism spectrum conditions: an investigation 
of the female autism phenotype. J Autism Dev Disord. (2016) 46:3281-94. doi: 10.1007/s10803-016-2872-8

41. Mackin ML, Loew N, Gonzalez A, Tykol H, Christensen T. Parent perceptions of sexual education needs for their children with autism. J Pediatr Nurs. (2016) 31:608-18. doi: 10.1016/j.pedn.2016.07.003

42. Sala G, Hooley M, Attwood T, Mesibov GB, Stokes MA. Autism and intellectual disability: a systematic review of sexuality and relationship education. Sex Disabil. (2019) 37:353-82. doi: 10.1007/s11195-019-09577-4

43. Brooks E. Opposing Forces? Autism and dating, romance, and sexuality in the mainstream media. Can. J. Disabil. Stud. (2018) 7:161-86. doi: $10.15353 /$ cjds.v7i2.428

44. Hannah LA, Stagg SD. Experiences of sex education and sexual awareness in young adults with autism spectrum disorder. J Autism Dev Disord. (2016) 46:3678-87. doi: 10.1007/s10803-016-2906-2

45. Holmes LG, Himle MB. Brief report: parent-child sexuality communication and autism spectrum disorders. J Autism Dev Disord. (2014) 44:296470. doi: 10.1007/s10803-014-2146-2

46. Bejerot S, Eriksson JM. Sexuality and gender role in autism spectrum disorder: a case control study. PLoS ONE. (2014) 9:e87961. doi: 10.1371/journal.pone.0087961

47. Byers ES, Nichols S, Voyer SD. Challenging stereotypes: sexual functioning of single adults with high functioning autism spectrum disorder. J Autism Dev Disord. (2013) 43:2617-27. doi: 10.1007/s10803-013-1813-z

48. Dewinter J, De Graaf H, Begeer S. Sexual orientation, gender identity, and romantic relationships in adolescents and adults with autism spectrum disorder. J Autism Dev Disord. (2017) 47:2927-34. doi: 10.1007/s10803-017-3199-9

49. George R, Stokes MA. Gender identity and sexual orientation in autism spectrum disorder. Autism. (2018) 22:97082. doi: $10.1177 / 1362361317714587$

50. George R, Stokes MA. A quantitative analysis of mental health among sexual and gender minority groups in ASD. J Autism Dev Disord. (2018) 48:205263. doi: 10.1007/s10803-018-3469-1

51. Gilmour L, Schalomon PM, Smith V. Sexuality in a community based sample of adults with autism spectrum disorder. Res Autism Spectr Disord. (2012) 6:313-8. doi: 10.1016/j.rasd.2011.06.003

52. Haracopos D, Pedersen L. Sexuality and Autism: A National Survey in Denmark. Bagsvaerd: Centre for Autism (1992). Available online at: https:// autismuk.com/autism/sexuality-and-autism/sexuality-and-autism-danishreport/ (accessed march 23, 2021).

53. Hellemans H, Roeyers H, Leplae W, Dewaele T, Deboutte D. Sexual behavior in male adolescents and young adults with autism spectrum disorder and borderline/mild mental retardation. Sex Disabil. (2010) 28:93104. doi: 10.1007/s11195-009-9145-9

54. Hillier A, Gallop N, Mendes E, Tellez D, Buckingham A, Nizami A, et al. LGBTQ+ and autism spectrum disorder: experiences and challenges. Int J Transgend Health. (2019) 21:98-110. doi: 10.1080/15532739.2019.15 94484

55. May T, Pang KC, Williams K. Brief report: sexual attraction and relationships in adolescents with autism. J Autism Dev Disord. (2017) 47:19106. doi: 10.1007/s10803-017-3092-6

56. Cooper K, Smith LG, Russell AJ. Gender identity in autism: sex differences in social affiliation with gender groups. J Autism Dev Disord. (2018) 48:39954006. doi: 10.1007/s10803-018-3590-1

57. Øien RA, Cicchetti DV, Nordahl-Hansen A. Gender dysphoria, sexuality and autism spectrum disorders: a systematic map review. J Autism Dev Disord. (2018) 48:4028-37. doi: 10.1007/s10803-018-3686-7

58. Strang JF, Kenworthy L, Dominska A, Sokoloff J, Kenealy LE, Berl $\mathrm{M}$, et al. Increased gender variance in autism spectrum disorders and attention deficit hyperactivity disorder. Archiv Sex Behav. (2014) 43:152533. doi: 10.1007/s10508-014-0285-3

59. Walsh RJ, Krabbendam L, Dewinter J, Begeer S. Brief report: gender identity differences in autistic adults: associations with perceptual and socio-cognitive profiles. J Autism Dev Disord. (2018) 48:4070-8. doi: 10.1007/s10803-018-3702-y

60. Williams PG, Allard AM, Sears L. Case study: cross-gender preoccupations in two male children with autism. J Autism Dev Disord. (1996) 26:63542. doi: $10.1007 / \mathrm{BF} 02172352$
61. DeVries ALC, Noens ILJ, Cohen-Kettenis PT, van BerckelaerOnnes IA, Doreleijers T. Autism spectrum disorders in gender dysphoric children and adolescents. J Autism Dev Disord. (2010) 40:930-6. doi: 10.1007/s10803-010-0935-9

62. Jones RM, Wheelwright S, Farrell K, Martin E, Green R, Di Ceglie $\mathrm{D}$, et al. Brief report: female-to-male transsexual people and autistic traits. J Autism Dev Disord. (2012) 42:301-6. doi: 10.1007/s10803-011$1227-8$

63. Pasterski V, Gilligan L, Curtis R. Traits of autism spectrum disorders in adults with gender dysphoria. Archiv Sex Behav. (2013) 43:38793. doi: 10.1007/s10508-013-0154-5

64. Stagg SD, Vincent J. Autistic traits in individuals self-defining as transgender or nonbinary. Eur Psychiatry. (2019) 61:1722. doi: 10.1016/j.eurpsy.2019.06.003

65. Nabbijohn AN, van der Miesen AIR, Santarossa A, Peragine D, de Vries ALC, Popma A, et al. Gender variance and the autism spectrum: an examination of children ages 6-12 years. J Autism Dev Disord. (2019) 49:157085. doi: 10.1007/s10803-018-3843-Z

66. George R, Stokes MA. Sexual orientation in autism spectrum disorder. Autism Res. (2018) 11:133-41. doi: 10.1002/aur.1892

67. Bush HH. Dimensions of sexuality among young women, with and without autism, with predominantly sexual minority identities. Sex Disabil. (2019) 37:275-92. doi: 10.1007/s11195-018-9532-1

68. Marriage S, Wolverton A, Marriage K. Autism spectrum disorder grown up: a chart review of adult functioning. J Can Acad Child Adolesc Psychiatry. (2009) 18:322-8.

69. American Psychiatric Association. Diagnostic and Statistical Manual of Mental Disorders DSM-5. 5th ed. Washington, DC: American Psychiatric Association (2013). doi: 10.1176/appi.books.9780890425596

70. Hancock GI. Socio-sexual functioning in Autism Spectrum Disorder [Doctoral thesis]. Deakin University, Melbourne, Australia (2017).

71. Cederlund M, Hagberg B, Gillberg C. Asperger syndrome in adolescent and young adult males. Interview, self-and parent assessment of social, emotional, and cognitive problems. Res Dev Disabil. (2010) 31:28798. doi: 10.1016/j.ridd.2009.09.006

72. Hosmer DW, Lemeshow S. Applied Logistic Regression. New York, NY: John Wiley and Sons (2000).

73. Lutchmaya S, Baron-Cohen S, Raggatt P, Knickmeyer R, Manning JT. 2nd to 4th digit ratios, fetal testosterone and estradiol. Early Hum Dev. (2004) 77, 23-28. doi: 10.1016/j.earlhumdev.2003.12.002

74. Auyeung B, Baron-Cohen S, Ashwin E, Knickmeyer R, Taylor K, Hackett G. Fetal testosterone and autistic traits. Br J Psychol. (2009) 100:122. doi: $10.1348 / 000712608 \times 311731$

75. Manning JT, Baron-Cohen S, Wheelwright S, Sanders G. The 2nd to 4th digit ratio and autism. Dev Med Child Neurol. (2001) 43:1604. doi: 10.1111/j.1469-8749.2001.tb00181.x

76. Baron-Cohen S, Auyeung B, Nørgaard-Pedersen B, Hougaard DM, Abdallah MW, Melgaard L, et al. Elevated fetal steroidogenic activity in autism. Mol Psychiatry. (2015) 20:369-76. doi: 10.1038/mp.2014.48

77. Baron-Cohen S, Tsompanidis A, Auyeung B, Nørgaard-Pedersen B, Hougaard DM, Abdallah M, et al. Foetal oestrogens and autism. Mol Psychiatry. (2020) 25:2970-8. doi: 10.1038/s41380-019-0454-9

78. Kung KT, Spencer D, Pasterski V, Neufeld S, Glover V, O'Connor TG, et al. No relationship between prenatal androgen exposure and autistic traits: convergent evidence from studies of children with congenital adrenal hyperplasia and of amniotic testosterone concentrations in typically developing children. J Child Psychol Psychiatry. (2016) 57:1455-62. doi: 10.1111/jcpp.12602

79. Leinung $\mathrm{M}, \mathrm{Wu} \mathrm{C}$. The biologic basis of transgender identity: 2D: 4D finger length ratios implicate a role for prenatal androgen activity. Endocr Pract. (2017) 23:669-71. doi: 10.4158/EP161528.OR

80. Manning JT. Prenatal sex steroids and transgender identity: is there a link with digit ratio? Endocr Pract. (2017) 23:738-40. doi: 10.4158/EP171843.CO

81. Gilmour H. Sexual Orientation and Complete Mental Health. Statistics Canada, Catalogue no. 82-003-X Health Reports (2019). p. 3-10.

82. Hull L, Lai MC, Baron-Cohen S, Allison C, Smith P, Petrides KV, et al. Gender differences in self-reported camouflaging in autistic and non-autistic adults. Autism. (2020) 24:352-63. doi: 10.1177/1362361319864804 
83. Lai MC, Lombardo MV, Ruigrok AN, Chakrabarti B, Auyeung B, Szatmari P, et al. Quantifying and exploring camouflaging in men and women with autism. Autism. (2017) 21:690-702. doi: 10.1177/13623613166 71012

84. Hiller RM, Young RL, Weber N. Sex differences in pre-diagnosis concerns for children later diagnosed with autism spectrum disorder. Autism. (2016) 20:75-84. doi: 10.1177/1362361314568899

85. Baron-Cohen S, Wheelwright S, Skinner R, Martin J, Clubley E. The autismspectrum quotient (AQ): evidence from Asperger syndrome/high-functioning autism, males and females, scientists and mathematicians. J Autism Dev Disord. (2001) 31:5-17. doi: 10.1023/A:1005653411471
Conflict of Interest: The authors declare that the research was conducted in the absence of any commercial or financial relationships that could be construed as a potential conflict of interest.

Copyright $\odot 2021$ Joyal, Carpentier, McKinnon, Normand and Poulin. This is an open-access article distributed under the terms of the Creative Commons Attribution License (CC BY). The use, distribution or reproduction in other forums is permitted, provided the original author(s) and the copyright owner(s) are credited and that the original publication in this journal is cited, in accordance with accepted academic practice. No use, distribution or reproduction is permitted which does not comply with these terms. 